\title{
Microzonation Map of Liquefaction Potential for Sharjah, United Arab Emirates
}

\author{
Maher Omar \\ Department of Civil and Environmental Engineering \\ University of Sharjah, P.O. Box 27272, Sharjah, UAE \\ momar@sharjah.ac.ae
}

\begin{abstract}
Seismic microzonation maps can play a significant role in the assessment of liquefaction potential in seismic design and in mitigating the consequences of earthquakes. The aim of this study includes the development of a simplified procedure for the assessment of seismic liquefaction of local soil data to determine the factor of safety against liquefaction. Soil database were collected from over 230 boreholes to develop local site liquefaction potential maps in the area. Site effects were then integrated in the Geographic Information System (GIS) platform for combined hazard assessment presentations. The Emirates of Sharjah is zoned indicating regions of different liquefaction potential and regions of high vulnerability to seismic hazard.
\end{abstract}

Keywords: Liquefaction, Microzonation Maps, Site effects, Seismic hazard, United Arab Emirates

\section{Introduction}

United Arab Emirates (UAE) receives earthquakes at around the Zagros fault, this is due to its proximity to Iran a country known for its catastrophic earthquakes that destroy structures like buildings, houses etc. In 2014, an earthquake in southern Iran, reported to measure 5.5 on the open ended Richter scale, occurred in different parts of UAE, although UAE does not suffer the same magnitude of earthquakes that Iran and Japan suffer, it is still a necessity to be in the safe zone for this particular matter.

The authors collected and analyzed over 230 boreholes data from Sharjah Municipality and others for different locations in the city as shown in Fig. 1. Many of the samples were collected from project sites where soils used as backfill materials. The selections were based on the soils used for projects such as sub-base, sub-grade, below sub-grade, below foundation, below slab on grade, and general filling.

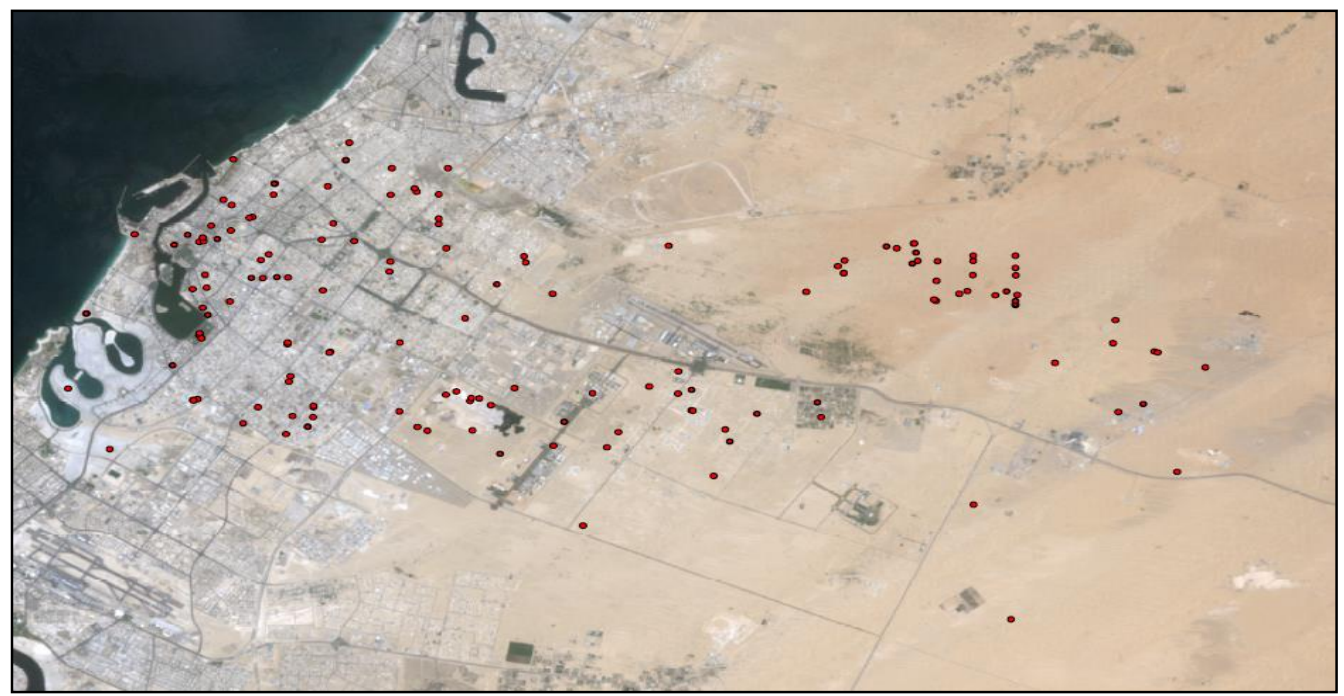

Fig. 1: Boreholes locations in Sharjah City. 
The present study aims at performing analysis on the influence of local soil conditions on ground response during earthquakes at various locations in the Emirates of Sharjah, UAE. The specific objective of this study is to estimate the liquefaction potential and prepare maps indicating zones of high vulnerability to seismic hazard

\section{Geology \& Seismicity of the Area}

UAE has a mountain belt along the eastern coast on the Gulf of Oman, fifth of it is desert, which means that it is geographically located in a unique location. The western part of the UAE is facing the subduction boundary across the Arabian Gulf opposite the Hurmuz Straits, one of the most seismically active zones in the world.

The city of Sharjah lies in the desert part of the UAE as shown in Fig. 2. It is one of the western cities that faces the Zagros folded belt, one of the most active faults in the world, through Arabian Gulf in the southern of Iran. The main city lies on the Arabian Gulf and other parts of the city lie on the Gulf of Oman like Khorfakkan, Kalbah and dibba. It is located in the geological window between altitudes ( $2525^{\prime} \mathrm{N}$ and $\left.2514^{\prime} \mathrm{N}\right)$ and (55 45' E and $\left.5520^{\prime} \mathrm{E}\right)$.

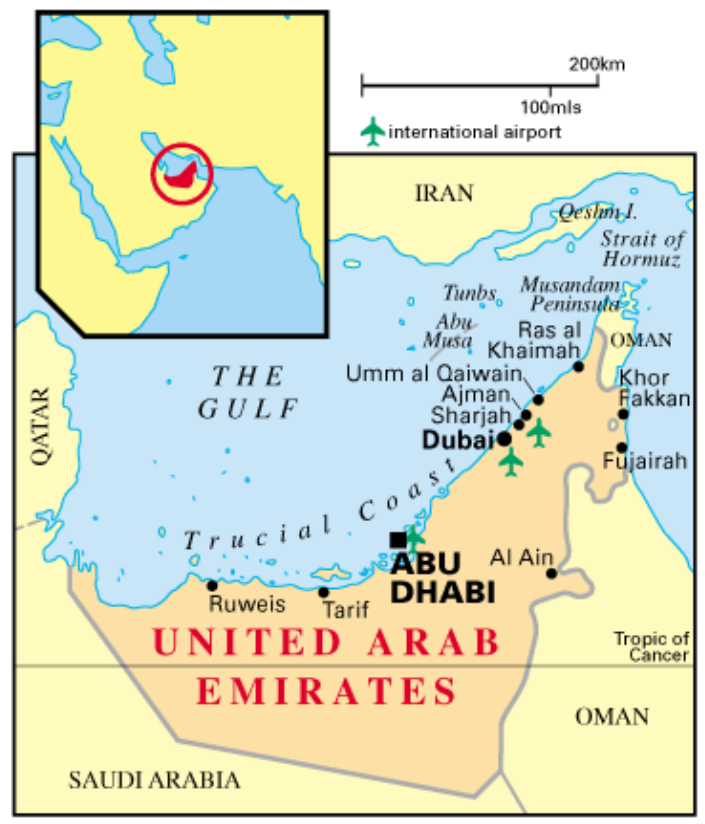

Fig. 2: Location of the UAE [1].

The general idea about the UAE is that there is little or no earthquake activity. However, the United Arab Emirates (UAE) is not as safe from earthquake disasters as often assumed. In March 2002, and according to [2], the Mb 5 earthquake shocked al Masafi area (25.24N 56.15E), northeast of UAE with its epicenter at $16 \mathrm{~km}$ depth. The strong motions recorded in December 10, 2002 and April 25, 2003, and the several small earthquakes recorded since that time, representing sufficient evidence of the existence of considerable seismic activity in the UAE.

According to [2] as reported by [2] outlined that this seismic activity attributed to the regional geologic settings and local geology of the UAE:

A. Major faults of unknown activity level have been mapped as transecting the UAE

B. The horn formed by the territory of the UAE penetrates into the plate- boundary of collision between the Arabian Peninsula and Asia, thus accumulating stresses

C. The Zagros Mountain is a folded belt that extends for about $1500 \mathrm{~km}$ in northwest-southeast direction along the western part of Iran and the north-eastern part of Iraq from Oman in the southeast to the Turkish borders in the northwest as shown in Fig. 3. The occurrences of earthquake events in the Zagros province define a zone, about $200 \mathrm{~km}$ wide, which runs parallel to the folded belt. The majority of the earthquakes occur in the crustal part of the Arabian plate that underlies the Zagros folded belt because it is one of the most active faults in the world. 
For example, a recent study of the historical seismicity of Iraq shows that most of the moderate to large historical events occurred in eastern Iraq along the Zagros folded belt.

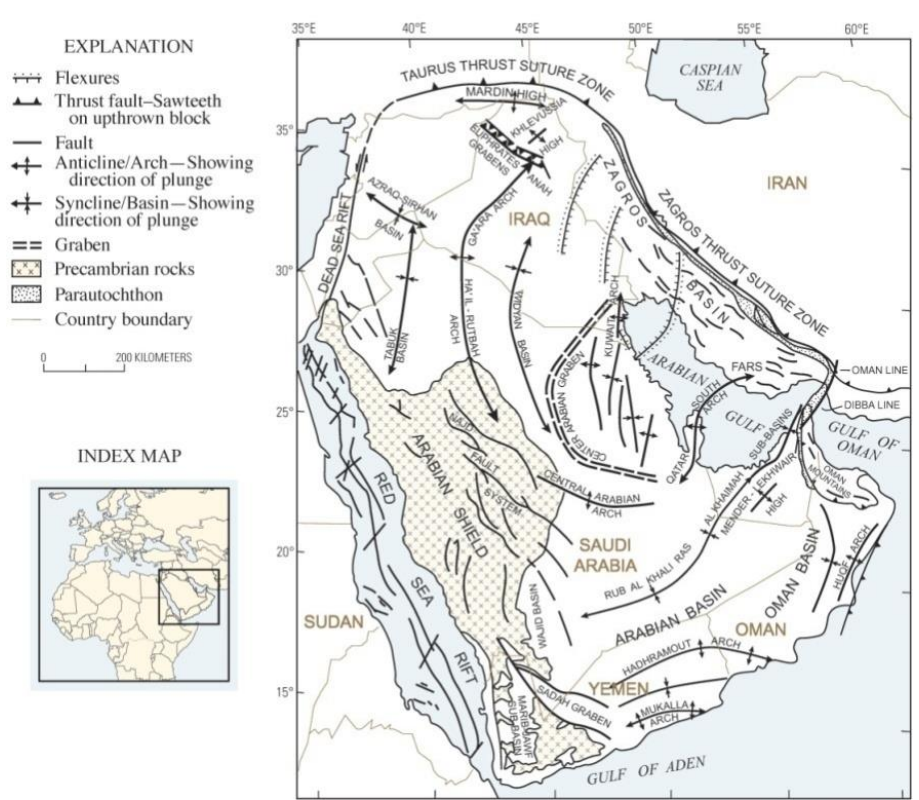

Fig. 3: Tectonics and geologic structure of the Arabian plate with Zagros folded belt [5].

D. Makran subduction zone: the area where Oman Gulf subducts under the Eurasian plate. It is an oceanic crust, which extends eastward to Owen Fracture zone along the Indian plate boundary. This oceanic crust descends below the continental crust along Makran subduction trench. This zone is capable of producing very strong earthquakes. For instance, the maximum regional observed earthquake on 11/27/1945, which is considered in this study, had a magnitude $(\mathrm{Mb}=8.2)$ at about $750 \mathrm{~km}$ from the UAE.

\section{Liquefaction and Its Importance}

Liquefaction occurs when seismic waves generated from an earthquake vibrate and disperse the soil particles from each other, this dispersion forms voids in the soil which in turn permits water to flow between the soil particles; reducing the shear strength caused by the frictional force these particles causing the soil to be more fluid. The strength reduction that occurs is immense and causes the foundation of structures to slip into the soil quickly, a test was made on a light modeled house that rested on saturated soil; the entire system was shaken by a small vibrator and caused the soil to liquefy, allowing the modeled house to slip inside the ground. This proves that liquefaction is an important problem that should be acknowledged.

\section{Data Collection \& General Classification}

Data were collected from over 230 different sites that considerably extend over Sharjah city. The boreholes selected with overburden thickness varying from $1 \mathrm{~m}$ to $30 \mathrm{~m}$ to represent typical geological features within the city and used for the site response analysis. The exact GPS locations for all boreholes were obtained from Directorate of Town Planning and a base map of all boreholes was prepared as shown in Fig. 1. In Sharjah City, mainly sandy soils with different densities are found. In some few layers, gravel and silt are encountered. Most of the boreholes consist of various layers, which are either one of these material types or a combination of two or more.

\section{Estimation of Ground Motion Signal}

The input ground motion considered for this study is the Chalfant Valley (1986/07/21 14:42) with M=6.2 recorded by Long Valley Dam (L Abut) station. The reason for selecting this ground motion is based on two factors. First, the magnitude of most effective earthquakes that originated from southern Iran and affected our study area is between 6.0 and 6.5. Second, 
peak ground acceleration for Sharjah city in 50 years and $10 \%$ probability is between $0.06-0.09$ as indicated earlier. Chalfant Valley's PGA falls within this range.

\section{Procedures}

This research paper was based on procedures that were followed in the lab, which include:

1. Analyzing the boreholes, that were inserted inside the grounds of Sharjah, by means of classifying the type of soil (percentage of fines), standard penetration test (SPT) in each layer, and the water table depth.

2. This information was inserted into Microsoft Access as data, and then plotted as points on the map using Google Earth Pro.

3. The representative boreholes selected were based on specific criteria to be followed, which include:

4. Locating the least elevation for each borehole inserted.

5. Searching for the least SPT in each layer.

6. $\quad$ Finding the water table closest to the surface.

7. The representative boreholes selected were minimized for the sake of simplicity: therefore, 200 of the least competent boreholes were plotted as zones.

\section{Calculation of Liquefaction}

The calculation of liquefaction is allocated into three different parts:

- Calculation of stress due to earthquakes (Called: Cyclic Stress Ratio - CSR)

- Calculation of soil strength (Called: Cyclic Resistance Ratio - CRR)

- Calculation of Factor of Safety against liquefaction (FS)

\subsection{Cyclic Stress Ratio}

Cyclic Stress Ratio (CSR) is a parameter that indicates the average shear stress produced by the seismic pulses on a soil layer. This stress can be calculated using the equation 1 proposed by [6], which states that the stress due to earthquakes is the ratio between total overburden stress and the effective overburden stress of soil multiplied by weighing, acceleration and stress reduction factors.

$$
\mathrm{CSR}=0.65 \times \frac{\sigma_{0}}{\sigma_{0}^{\prime}} \times \mathrm{a}_{\max } \times \mathrm{r}_{\mathrm{d}}
$$

Where:

$0.65=$ the weighing factor to calculate the number of stress cycles required to produce the same pore water pressure in an earthquake motion.

$\sigma_{0}=$ the total overburden stress.

$\sigma_{0},=$ the effective overburden stress.

$\mathrm{a}_{\max }=$ ground acceleration .

$r_{d}=$ coefficient for stress reduction.

An example of the SPT-based database used for estimating liquefaction resistance is shown in Fig. 4

\subsection{Cyclic Resistance Ratio (CRR)}

Cyclic Resistance Ratio (CRR) refers to the capability in soil layers to resist liquefaction produced by earthquakes or tremors. CRR depends on the Standard Penetration Test (SPT) values; therefore the SPT value should be adjusted to Corrected SPT values. This was completed using two methods, correction for blow count data and fines content corrections. 

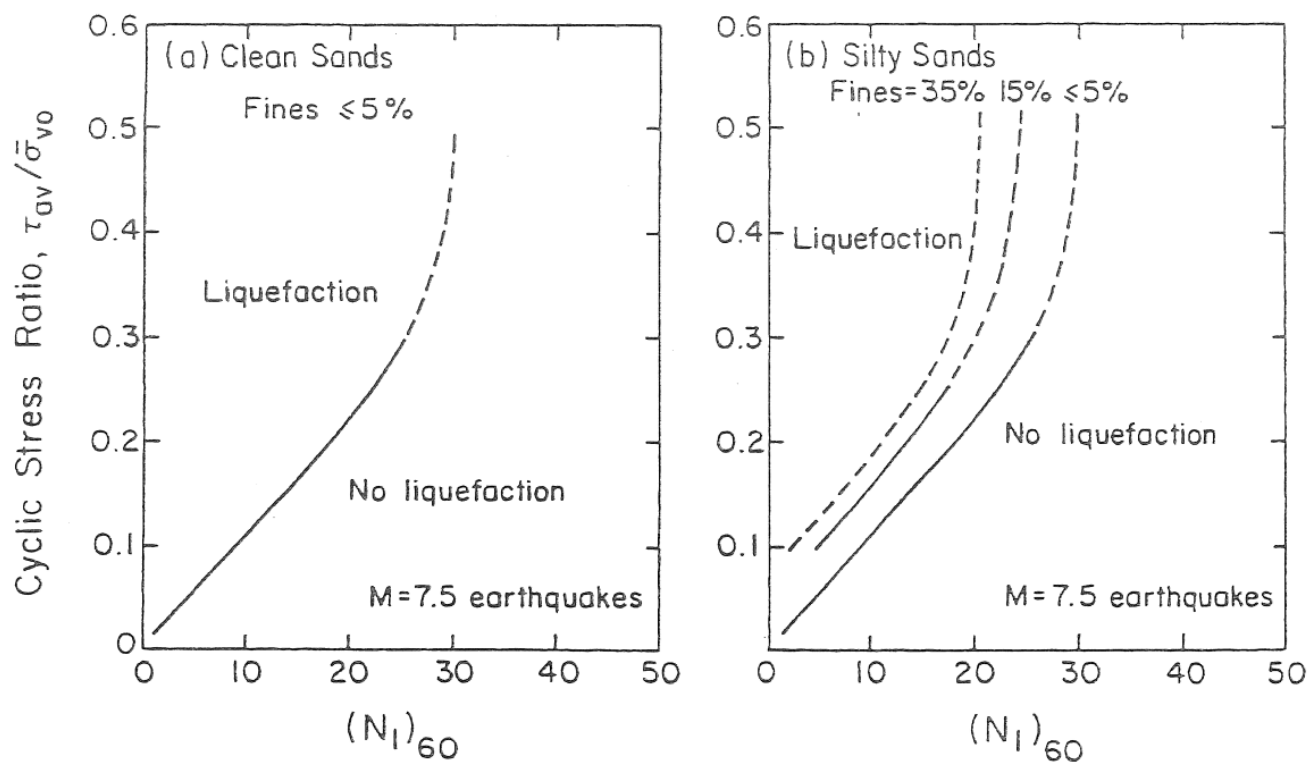

Fig. 4: SPT-based database used for estimating liquefaction resistance [7].

\subsection{Correction for Blow Counts}

The standard penetration test (SPT) requires a correction factor (N1) 60 given by equation 2 due to the loss of energy with each penetration. The following equation is denoted below:

$$
\left(\mathrm{N}_{1}\right)_{60}=\mathrm{N} \times \mathrm{C}_{\mathrm{n}} \times \mathrm{C}_{\mathrm{e}} \times \mathrm{C}_{\mathrm{b}} \times \mathrm{C}_{\mathrm{r}} \times \mathrm{C}_{\mathrm{s}}
$$

Where:

$\mathrm{C}_{\mathrm{n}}$ : depth correction

$\mathrm{C}_{\mathrm{e}}$ : energy correction

$\mathrm{C}_{\mathrm{b}}$ : borehole diameter correction

$\mathrm{C}_{\mathrm{r}}$ : length correction

$\mathrm{C}_{\mathrm{s}}$ : sampler correction

$\mathrm{N}$ is the original value

But through this project only $C_{n}$ has been considered and lies between 0.4 and $1.7(0.4 \leq \mathrm{Cn} \leq 1.7)$

\subsection{Fines Content Correction}

For this correction different methods can be used, but for this project Idriss and Seed's method has been adopted and given by equation 3 . This method depends on the percentage of fines found in the data given for soil.

$$
\left(\mathrm{N}_{1}\right)_{60 \mathrm{f}}=\alpha+\beta\left(\mathrm{N}_{1}\right)_{60}
$$

Where:

$\alpha=0 ; \beta=1.0 \quad$ for $\mathrm{FC} \leq 5 \%$

$\alpha=\mathrm{e}^{\left[1.76-\left(190 / \mathrm{FC}^{2}\right)\right]} ; \beta=0.99+\mathrm{FC}^{1.5} / 1000 \quad$ for $5<\mathrm{FC} \leq 35 \%$

$\alpha=5.0 ; \beta=1.2 \quad$ for $\mathrm{FC} \geq 35 \%$

$\left(\mathrm{N}_{1}\right)_{60 \mathrm{f}}$ is the corrected SPT value and FC is the percentage of fines. 


\subsection{Calculation of CRR}

$$
\mathrm{CRR}=\frac{\mathrm{a}+\left(\mathrm{c} \times\left(\mathrm{N}_{1}\right)_{60 \mathrm{f}}\right)+\left(\mathrm{e} \times\left(\mathrm{N}_{1}\right)_{60 \mathrm{f}}{ }^{2}\right)+\left(\mathrm{g} \times\left(\mathrm{N}_{1}\right)_{60 \mathrm{f}}{ }^{3}\right)}{1+\left(\mathrm{b} \times\left(\mathrm{N}_{1}\right)_{60 \mathrm{f}}\right)+\left(\mathrm{d} \times\left(\mathrm{N}_{1}\right)_{60 \mathrm{f}}{ }^{2}\right)+\left(\mathrm{f} \times\left(\mathrm{N}_{1}\right)_{60 \mathrm{f}}{ }^{3}\right)+\left(\mathrm{h} \times\left(\mathrm{N}_{1}\right)_{60 \mathrm{f}}{ }^{4}\right)}
$$

Where:

$\left(\mathrm{N}_{1}\right)_{60 \mathrm{f}}$ is the corrected SPT value

$\mathrm{a}=0.048, \mathrm{~b}=-0.1248, \mathrm{c}=-0.004721, \mathrm{~d}=0.009578, \mathrm{e}=0.0006136, \mathrm{f}=-0.003285, \mathrm{~g}=-1.676 \times 10^{-5}, \mathrm{~h}=3.714 \times 10^{-}$

\section{Factor of Safety}

This factor is the ratio between CSR and CRR is shown in equation 5, and liquefaction can be indicated using this factor. Which means is the FS is less than one the liquefaction will occur in that certain layer, but if it was greater than one then no liquefaction will happen.

$$
\mathrm{FSL}=\frac{\mathrm{CRR}}{\mathrm{CSR}}
$$

\section{Analysis and Results}

Table 1 below reveal the factors of safety for each layer (in meters) for each zone, these zones were produced based on our selection for the representative boreholes. The process of obtaining a representative soil profile for each zone include: (1) Verification of all available soil data for each borehole location, (2) All borehole data from each zone are then compared, (3) Representative profile for each zone is selected. These steps were made for liquefaction study only, and not for any other reason, especially when dealing with new construction.

Table 1: Results of Representative Soil Profiles for All Zones.

\begin{tabular}{|l|l|l|l|l|l|}
\hline Properties & Zone 1 & Zone 2 & Zone 3 & Zone 4 & Zone 5 \\
\hline Depth $(\mathrm{m})$ & $0-15$ & $0-15$ & $0-15$ & $0-15$ & $0-15$ \\
\hline $\mathrm{N}_{\mathrm{m}}(\mathrm{Blow} / \mathrm{m})$ & $12-60$ & $13-40$ & $12-48$ & $8-50$ & $2-47$ \\
\hline $\begin{array}{l}\left(\mathrm{N}_{1}\right)_{60} \\
(\mathrm{Blow} / \mathrm{m})\end{array}$ & $14-78$ & $16-50$ & $14-58$ & $10-60$ & $7-62$ \\
\hline Fines \% & $3-20$ & $20-35$ & $20-40$ & $15-35$ & $20-40$ \\
\hline $\mathrm{D}_{50}(\mathrm{~mm})$ & $0.12-0.15$ & $0.11-0.14$ & $0.10-0.15$ & $0.10-0.14$ & $0.12-0.15$ \\
\hline $\begin{array}{l}\text { Unit weight } \\
\left(\mathrm{Kg} / \mathrm{m}^{3}\right)\end{array}$ & $12.5-20$ & $16-19$ & $17.5-20$ & $15-18$ & $14-18$ \\
\hline $\mathrm{CSR}$ & $0.125-0.225$ & $0.19-0.23$ & $0.12-0.3$ & $0.12-0.25$ & $0.22-0.27$ \\
\hline $\mathrm{CRR}$ of & $0.15-0.25$ & $-0.4-0.7$ & $-3.15-0.44$ & $-0.143-0.48$ & $-0.5-0.04$ \\
\hline $\begin{array}{l}\text { Factor } \\
\text { Safety }\end{array}$ & $1.03-2.6$ & $-2.4-2.3$ & $-12.5-3.4$ & $-0.9-2.8$ & $-3.1-1.19$ \\
\hline $\begin{array}{l}\text { No. of layers } \\
\text { susceptible to } \\
\text { liquefaction }\end{array}$ & 0 & 1 & 2 & 3 & 4 or more \\
\hline
\end{tabular}

\section{Conclusion}

Liquefaction is a factor that shouldn't be underestimated, because of this problem many buildings sunk into the ground due to lack of caution. In this project, about 230 boreholes were spread around Sharjah in order to study the liquefaction within the soil layers. The boreholes were examined based on the classification, SPT, and water table in each layer; therefore the CRR and CSR can be calculated in order to know the factor of safety in each zone. A hazard map was developed showing the factor of safety within each zones depending on the number of layers, in Fig. 5 the zones are distinguished based on the 
colors and it can be used to indicate which zones have a high possibility to liquefy (indicated as red/orange) and which zones have a low possibility to liquefy (indicated in yellow, green, and orange). Notice the zones closest to the ocean are prone to liquefy since the water seeps into the ground moving the water table towards the surface.

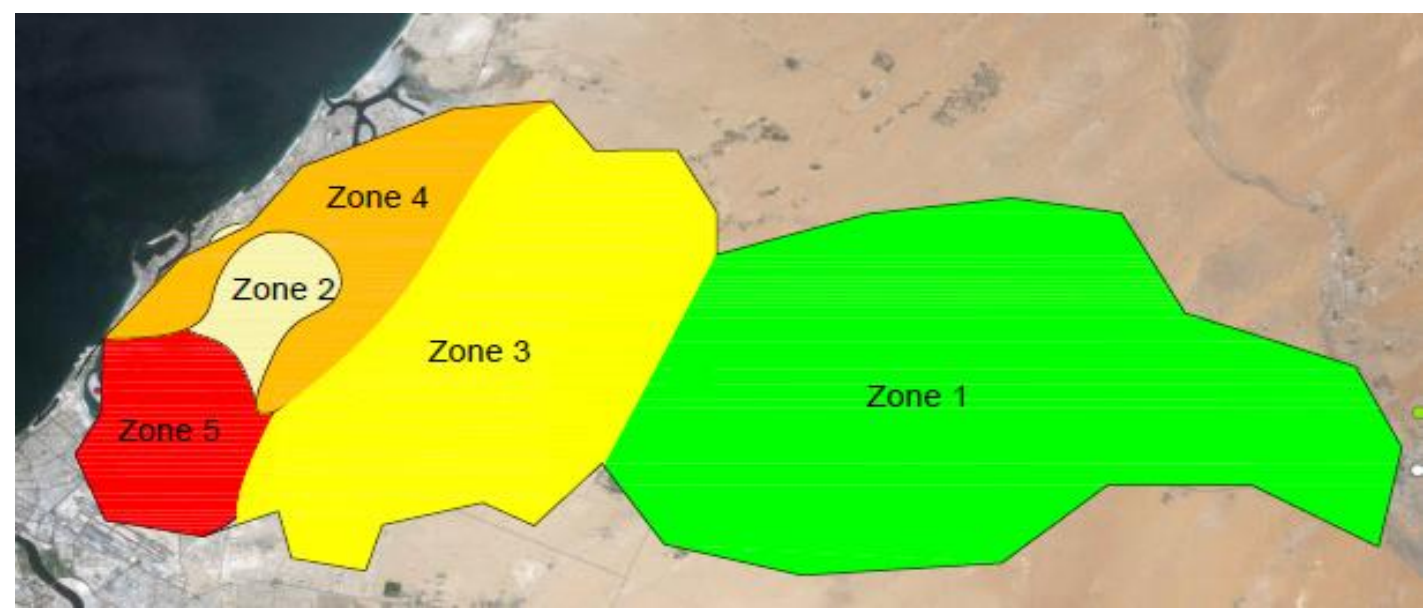

Fig. 5: Microzonation map for liquefaction in Sharjah, UAE.

\section{Acknowledgements}

I would like acknowledge the work done by my undergraduate students, Abdulrahman Barakat and Omar Raed Abuodeh, for aiding in this research and providing enough information to produce the paper.

\section{References}

[1] http://www.ameinfo.com/images/maps/uae.gif. "Location of the UAE"

[2] A. Jamal and A. S. A-Homoud, "Seismic hazard assessment of United Arab Emirates and its surroundings," Journal of Earthquake Engineering, vol. 8, no. 6, pp. 817-837, 2004.

[3] UNESCO, "Report for AFESD and IDB assessment and mitigation of earthquake risk in the arab region," 1983.

[4] A. I. H. Malkawi, S. Barakat, A. Shanableh, W. Al Bdour, M. Omar, and S. Altoubat, "Seismic Hazard Assessment and Mitigation of Earthquake Risk in the United Arab Emirates," Jordan University of Science and Technology and the Deanship of Research and Higher Studies, University of Sharjah, United Arab Emirates, 2007.

[5] J. E. Fox and T. S. Ahlbrandt, "U.S. Geological survey bulletin," 2002.

[6] H. B. Seed and I. M. Idriss, "Simplified procedure for evaluating soil liquefaction potential," Journal Geotechnical Engineering Div. ASCE, vol. 97, no. 9, pp. 1249-1273, 1971.

[7] Idris and Boulanger, "Spt-Based Liquefaction Triggering Procedures," Report UCD/CGM-10/02, Center For Geotechnical Modeling, 2010. 